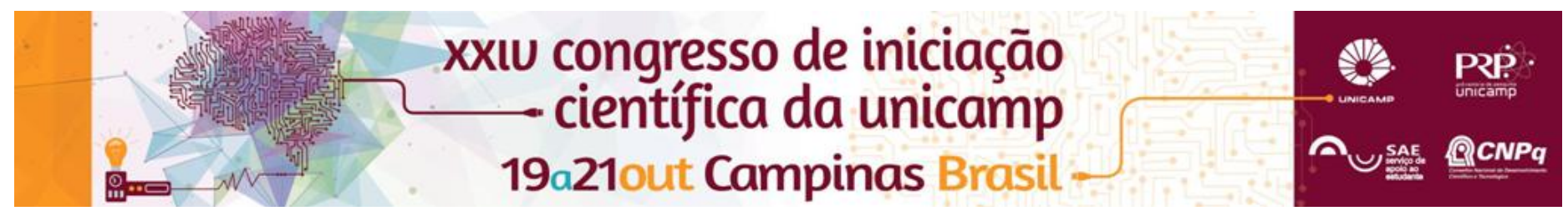

\title{
Caracterização de PLA modificado com elastômero e extensor de cadeia Joncryl ADR-6348
}

\author{
Kaan O. Guimarães*, Profa . Dra. Ana Rita Morales
}

\section{Resumo}

O poli(ácido Lático) (PLA) é um polímero biodegradável com grande potencial para utilização industrial, é versátil e apresenta um custo relativamente baixo de produção. Desta forma, sua produção e modificação são objetivos muito visados industrialmente. Porém, a aplicação do mesmo se limita devido à sua rigidez à temperatura ambiente. Este projeto de iniciação científica teve como objetivo o estudo da modificação do PLA pelo uso de um elastômero e um extensor de cadeia visando flexibilização e compatibilização do material. Foram preparadas amostras com e sem o extensor de cadeia, adicionando-se 0,5\% em massa do Joncryl ADR-6348 na composição de cada uma delas. Após o processamento, as misturas foram moldadas em uma prensa hidráulica com e submetidas aos testes de FTIR (Espectroscopia do infravermelho por transformada de Fourier), que verificam os grupos funcionais presentes na estrutura química das amostras. A próxima etapa a ser realizada seria a análise em DSC que avaliaria o comportamento térmico das amostras. Posteriormente, seria realizada uma cromatografia por permeação em gel (GPC) e microscopia eletrônica de varredura (SEM) das amostras e, a partir disso, as influências do extensor de cadeia e do elastômero seriam avaliadas completamente. Porém, o projeto foi interrompido devido à saída do aluno da Faculdade de Engenharia Química.

\section{Palavras-chave:}

poli(ácido Lático) (PLA), fontes renováveis, flexibilização de cadeia

\section{Introdução}

O poli(ácido Lático) (PLA) é obtido de fontes renováveis, tem um custo relativamente baixo de produção e pode ser processado com técnicas convencionais de processamento de polímeros. Porém, a ampla aplicação do PLA é limitada devido à sua rigidez a temperatura ambiente. Desta forma, a modificação do PLA visando melhoria de propriedades mecânicas tem sido amplamente estudada. O projeto visou a funcionalização e flexibilização do PLA possibilitando uma melhor caracterização do mesmo para ser aplicado em processos industriais.

\section{Resultados e Discussão}

O elastômero utilizado foi obtido experimentalmente por Zborowski et al., (2015) apresentando a seguinte composição: shell (camada externa), composta por metacrilato de metila-co-ácido itacônico (MMA-co-ITA); e core (camada interna), composta por poli (acrilato de butila-co-metacrilato de metila-co-ácido itacônico (BA-coMMA-co-ITA)

As amostras foram preparadas de acordo com as proporções apresentadas na Tabela 1. Preparou-se amostras com adição de 0,5\% de Joncryl ADR-6348 e sem a adição do extensor de cadeia.

\begin{tabular}{|c|c|c|}
\hline Amostra & PLA(\%) & $\begin{array}{c}\text { Elastômero } \\
\text { (\%) }\end{array}$ \\
\hline 1 & 90 & 10 \\
\hline 2 & 80 & 20 \\
\hline 3 & 70 & 30 \\
\hline
\end{tabular}

Tabela 1. Concentrações das amostras compostas por PLA e elastômero core-shell.

As amostras foram submetidas à caracterização por FTIR (Espectroscopia do infravermelho por transformada de Fourier), visando a identificação dos grupos funcionais presentes na estrutura química das amostras. Os espectros de FTIR obtidos foram analisados e notouse a banda de hidroxila em torno dos $3430 \mathrm{~cm}^{-1}$ na amostra sem extensor de cadeia e a diminuição da mesma na amostra com o extensor de cadeia. Isto pode estar relacionado à interação entre grupos epóxido dos extensores com grupos hidroxila $(\mathrm{OH})$ presentes em poliésteres. Percebeu-se também que picos referentes ao estiramento $\mathrm{C}$-O do extensor de cadeia não são observados no espectro.

\section{Conclusão}

Como o projeto não chegou à sua fase final, a caracterização do PLA não foi completa. A partir disso, o projeto pode servir como base de estudos para projetos futuros que visem a flexibilização do polímero.

\section{Agradecimentos}

Agradeço à minha professora, Dra. Ana Rita Morales por tudo o que me foi ensinado.

Al-Itry, R.; Lamnawar, K.; Maazouz, A. Improvement of thermal stability, rheological and mechanical properties of PLA, PBAT and their blends by reactive extrusion with functionalized epoxy. Polymer Degradation and Stability, p. 1-17, 2012

Cardoso, A.L.H; Cardosos, A; Galembeck, F. Obtenção e Caracterização de Látex Copoliméricos. Polímeros: Ciência eTecnologia, p.32-36, 1992.

NAJAFI, N.; HEUZEY, M.C.; CARREAU, P.J.; WOOD-ADAMS, P. M. Control of thermal degradation of polylactide (PLA)-clay nanocomposites using chain extenders. Polymer Degradation and Stability. v. 97, p. 554-565, 2012

Zborowski, L; Porto, D; Taparelli, J.R.; Mei, L.H.I. "Influência de temperatura e de ácido itacônico na síntese de partículas core-shell de acrilato de butila e metacrilato de metila vila polimerização em emulsão em processo semicontínuo", $13^{\circ}$ CONGRESSO BRASILEIRO DE POLÍMEROS, 2015 